\section{Case Reports in Neurology}

Case Rep Neurol 2020;12:161-168

DOI: 10.1159/000503094

Published online: December 14, 2020

2020 The Author(s)

Published by S. Karger AG, Basel

www.karger.com/crn

This article is licensed under the Creative Commons Attribution-NonCommercial 4.0 International License (CC BY-NC) (http://www.karger.com/Services/OpenAccessLicense) Usage and distribution for commercial purposes requires written permission.

\title{
Small Intracranial Aneurysms and Subarachnoid Hemorrhage: Is the Size Criterion for Risk of Rupture Relevant?
}

\author{
Karan Daga $^{\mathrm{a}} \quad$ Manish Taneja $^{\mathrm{b}} \quad$ Narayanaswamy Venketasubramanian ${ }^{\mathrm{b}}$ \\ aFaculty of Biology, Medicine and Health, The University of Manchester, Manchester, UK; \\ ${ }^{b}$ Raffles Neuroscience Centre, Raffles Hospital, Singapore, Singapore
}

\section{Keywords}

Small aneurysm rupture $\cdot$ Intracranial aneurysm $\cdot$ Subarachnoid hemorrhage $\cdot$ ISUIA

\section{Abstract}

The current understanding is that small intracranial aneurysms $(<7 \mathrm{~mm})$ are not at a significant risk for rupture. However, there have been several published series of rupture and subarachnoid hemorrhage from aneurysms $<5 \mathrm{~mm}$. Three cases of intracranial aneurysms rupturing at $<3 \mathrm{~mm}$ are presented in this paper. Patient age ranged between 38 and 57 years. The aneurysms were located in different parts of the circulation in the brain. This case series highlights that the size criterion alone is not adequate when evaluating patients with unruptured brain aneurysms for observational follow-up or treatment. 


\section{Case Reports in Neurology}

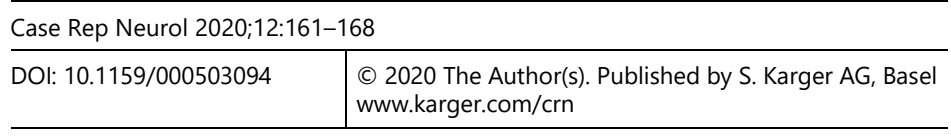

Daga et al.: Small Intracranial Aneurysms and Subarachnoid Hemorrhage: Is the Size Criterion for Risk of Rupture Relevant?

\section{Introduction}

It is felt that intracranial aneurysms are at risk for rupture when they reach $7 \mathrm{~mm}$ in size and above. The International Study of Unruptured Intracranial Aneurysms (ISUIA)-1 (1998) and ISUIA-2 (2003) suggested that there is a negligible risk of subarachnoid hemorrhage (SAH) in aneurysms that measure $<7 \mathrm{~mm}$ in size $[1,2]$. Our experience is contrary to these published studies with a number of ruptured aneurysms presenting with SAH that are $<5 \mathrm{~mm}$. A significant portion of them were $<3 \mathrm{~mm}$ in size at the time of the bleed. In this paper, we present 3 recent cases of aneurysmal SAH at smaller sizes. This suggests that the criterion for aneurysm size and SAH risk may not be applicable to the population as a whole, with other factors such as, but not limited to, background, ethnicity and genetic factors and aneurysm morphology possibly having a role to play.

\section{Case 1}

A 38-year-old female presented to Accident and Emergency with a severe headache as well as nausea and vomiting over a period of $1 \mathrm{~h}$. On arrival, her Glasgow Coma Scale score (GCS) was 15. She collapsed while being assessed, with her GCS dropping to 3. She was intubated, and a CT scan was done, which showed a massive SAH with an intraparenchymal hematoma in relation to an aneurysm, measuring 6.0 by $1.6 \mathrm{~cm}$. A CT angiogram showed a left posterior communicating artery (PComA) aneurysm measuring 3 by $2 \mathrm{~mm}$ in size. Emergency ventricular drainage and coiling were done successfully, and she was managed medically over the next month. Follow-up over a period of 4 months showed gradual neurological recovery with no focal deficits and some minor headaches.

\section{Case 2}

A 57-year-old female was brought to Accident and Emergency with a GCS of 3 after collapsing. CT scan showed SAH with maximal blood seen in relation to the right cerebellar pontine space. An angiogram showed an aneurysm located at the right proximal posterior cerebral artery (PCA; P1 segment) (Fig. 1). The aneurysm measured $2 \mathrm{~mm}$ in size and pointed posterolaterally. This was treated by coil embolization with complete occlusion. The patient is still in the hospital after 3 months and is under full assisted care. She is able to breathe normally with a tracheostomy in place and nasogastric tube feeding, but unable to move her limbs or speak.

\section{Case 3}

A 44-year-old woman collapsed and presented with a GCS of 3. CT scan showed a SAH with a $7.0-\mathrm{cm}$ left frontal lobe hematoma. A catheter angiogram showed a 3-mm anterior 


\section{Case Reports in Neurology}

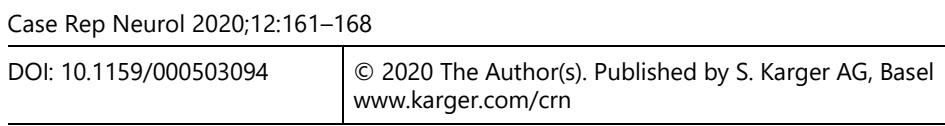
www.karger.com/crn

Daga et al.: Small Intracranial Aneurysms and Subarachnoid Hemorrhage: Is the Size Criterion for Risk of Rupture Relevant?

communicating artery (AComA) aneurysm with its rupture point at the apex (Fig. 2). This was subsequently treated with coil embolization. Despite best medical care and management, the patient is still in coma after nearly 4 months of care.

\section{Discussion}

The 3 cases we present include patients of different ages with intracranial aneurysms in different anatomical locations. All 3 patients had aneurysms that were $\leq 3 \mathrm{~mm}$ at the time of rupture. Despite medical care, only 1 patient had a favourable outcome.

The importance of a clinical guideline involving intracranial aneurysms cannot be understated. It is estimated that $4 \%$ of the population have intracranial aneurysms, which are often asymptomatic [3]. Aneurysmal SAH has a mortality rate of $44 \%$ within 30 days, with over half of the surviving patients suffering from irreversible brain damage $[4,5]$. The low reported rate of rupture and the relatively higher perioperative morbidity and mortality rates have made surgical or endovascular intervention of aneurysms of less than $5 \mathrm{~mm}$ a grey area.

The ISUIA-1 trial in 1998 reported that patients with no history of SAH had only a $0.05 \%$ risk of rupture per year of intracranial aneurysms that were $<10 \mathrm{~mm}$ in size [1]. The ISUIA-2 trial in 2003 found that patients with no history of SAH had a $0.1 \%$ risk of rupture per year of intracranial aneurysms that were $<7 \mathrm{~mm}$ in size [2]. However, many studies since have contradicted this finding.

In 2009, Joo et al. [6] reported 889 cases of intracranial aneurysms, of which 627 ruptured. The majority of ruptured aneurysms ( 451 cases, $71.8 \%$ ) were $<7 \mathrm{~mm}$, and the mean size at the time of the bleed was $6.28 \mathrm{~mm}$ [6]. The International Subarachnoid Aneurysm Trial (ISAT) from 2002 studied 2,143 patients with intracranial aneurysms and found that 1,124 of their patients (52.4\%) presented with aneurysms of less than $5 \mathrm{~mm}$ [7]. Beck et al. [8] found $59 \%$ of their 83 cases of intracranial aneurysms to be less than $7 \mathrm{~mm}$ at the time of rupture. In the cases we present, none of the three aneurysms were larger than $3 \mathrm{~mm}$, yet all three ruptured and caused a SAH.

Additionally, it is accepted that the need for intervention in larger aneurysms was justified as they would present with a more severe SAH. However, in the clinical study done by Dolati et al. [5], patients with a SAH caused by aneurysms $<5 \mathrm{~mm}$ also presented with poor Hunt and Hess scores (grades 4 and 5). As shown, Patients 2 and 3 presented herein both had unfavorable outcomes due to the rupture of small aneurysms $(\leq 3 \mathrm{~mm})$.

Apart from size, another major factor that may contribute to the risk of rupture may be location. Of our 3 patients, each had a single ruptured intracranial aneurysm located in a different artery: PComA, PCA, and AComA. As shown in Table 1, which comprises 2,508 cases of ruptured and unruptured intracranial aneurysms from multiple studies, the location of the aneurysm is highly variable. The AComA and PComA are shown to be a common site of intracranial aneurysms across the studies included, which was seen in our patients as well [8-12].

Beck et al. [8] compared patients with unruptured $(n=72)$ and ruptured $(n=83)$ intracranial aneurysms. They concluded that aneurysms of the anterior cerebral artery (ACA) and AComA are more likely to rupture than others, and conversely so for aneurysms of the middle 


\section{Case Reports in Neurology}

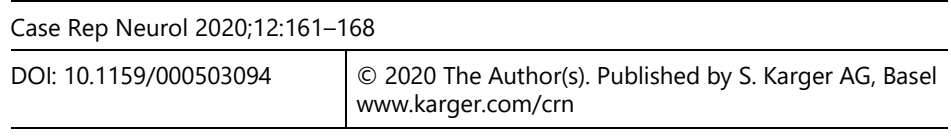

Daga et al.: Small Intracranial Aneurysms and Subarachnoid Hemorrhage: Is the Size Criterion for Risk of Rupture Relevant?

cerebral artery (MCA) [8]. Of their 83 ruptured aneurysms $<7 \mathrm{~mm}$, they reported that $44.9 \%$ were located at the ACA or AComA [8]. Albeit these studies do not represent a clear pattern of location and rupture, it may have an influence and should be considered when evaluating patients in practice.

Supporting observational follow-up of aneurysms, as opposed to treatment, was the perioperative morbidity and mortality rate of $10 \%$ reported in the ISUIA [5]. The ISAT compared the outcomes of clipping versus coiling in their 2,143 patients [7]. The ISAT reported a morbidity and mortality rate of 30.6 and $23.7 \%$ for neurosurgical clipping and endovascular coiling, respectively [7]. However, these reports were from 20 and 16 years ago, respectively [1, 5, 7].

Major advances in endovascular stenting have occurred in the past 2 decades, and the morbidity and mortality is now a fraction of that. In 2013, Wang et al. [9] reported a 5.5 and $2.8 \%$ rate, respectively, among 72 patients. In 2011, Gao et al. [10] found a morbidity and mortality of 4.2 and $1.3 \%$, respectively, in a cohort of 232 patients. Liang et al. [13] treated 110 intracranial aneurysms and had a morbidity and mortality of 5.6 and $0.9 \%$, respectively. All three of these studies used endovascular stent-assisted coiling $[9,10,13]$. Whilst the improvements in treatment success do not address the issue of the current size criterion's relevancy, they lower the risk of SAH from aneurysms $<5 \mathrm{~mm}$ due to their low perioperative risks.

As illustrated in our cases above, the size criterion for rupture may not be relevant. All 3 patients had a life-threatening hemorrhage with only one out of 3 patients having a favorable outcome. The 2 patients with adverse outcomes had been under follow-up at other institutions previously, and it was decided not to treat them due to their small size. Both are currently in institutionalized care. All 3 patients had aneurysms in different locations within the brain, indicating that the latter may not be related to rupture risk.

There were some limitations in our study. Primarily, as we only present 3 patients, we cannot draw a definitive conclusion regarding the size criterion and risk of rupture. A larger sample size would be needed to provide a better understanding of the effect of anatomical location as well. Secondly, there are numerous factors that need to be accounted for, such as age, ethnicity, history of smoking, hypertension, as risk factors for hemorrhage. A larger, multicentric study is needed. In addition, there is a need to study both ruptured and unruptured aneurysms to better understand the risk of rupture. As stated by Skodvin et al. [14], post-rupture morphology is not suitable to understand the original aneurysm and its rupture risk.

In conclusion, these cases suggest that the size criterion alone is not an optimal guideline while evaluating patients with unruptured aneurysms. There are other factors involved that are not fully understood and need further evaluation in large-scale studies in different population subgroups.

\section{Acknowledgements}

We would like to thank the patients mentioned in this paper for their help and contribution.

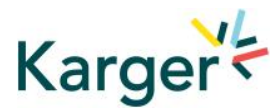




\section{Case Reports in Neurology}

Case Rep Neurol 2020;12:161-168

DOI: $10.1159 / 000503094$

2020 The Author(s). Published by S. Karger AG, Basel www.karger.com/crn

Daga et al.: Small Intracranial Aneurysms and Subarachnoid Hemorrhage: Is the Size Criterion for Risk of Rupture Relevant?

\section{Statement of Ethics}

Informed consent was given by the patients and their families for the publication of this report and the figures included. This study was conducted ethically in accordance with the Helsinki Declaration.

\section{Conflict of Interest Statement}

The authors have no conflicts of interest to declare.

\section{Funding Sources}

The authors have no funding sources to disclose.

\section{Author Contributions}

K.D. performed the literature search and prepared the drafts of the manuscript. M.T. was the radiologist for the patients presented, provided the figures, and helped prepare the manuscript. N.V. was involved with preparing and revising the manuscript.

\section{References}

1 International Study of Unruptured Intracranial Aneurysms Investigators. Unruptured intracranial aneurysms-risk of rupture and risks of surgical intervention. N Engl J Med. 1998 Dec;339(24):1725-33.

2 Wiebers DO, Whisnant JP, Huston J 3rd, Meissner I, Brown RD Jr, Piepgras DG, et al.; International Study of Unruptured Intracranial Aneurysms Investigators. Unruptured intracranial aneurysms: natural history, clinical outcome, and risks of surgical and endovascular treatment. Lancet. 2003 Jul;362(9378):103-10.

3 Keedy A. An overview of intracranial aneurysms. Mcgill J Med. 2006 Jul;9(2):141-6.

4 Olafsson E, Hauser WA, Gudmundsson G. A population-based study of prognosis of ruptured cerebral aneurysm: mortality and recurrence of subarachnoid hemorrhage. Neurology. 1997 May;48(5):1191-5.

5 Dolati P, Pittman D, Morrish WF, Wong J, Sutherland GR. The Frequency of Subarachnoid Hemorrhage from Very Small Cerebral Aneurysms (<5 mm): A Population-Based Study. Cureus. 2015 Jun;7(6):e279.

6 Joo SW, Lee SI, Noh SJ, Jeong YG, Kim MS, Jeong YT. What Is the Significance of a Large Number of Ruptured Aneurysms Smaller than 7 mm in Diameter? J Korean Neurosurg Soc. 2009 Feb;45(2):85-9.

7 Molyneux A, Kerr R, Stratton I, Sandercock P, Clarke M, Shrimpton J, et al.; International Subarachnoid Aneurysm Trial (ISAT) Collaborative Group. International Subarachnoid Aneurysm Trial (ISAT) of neurosurgical clipping versus endovascular coiling in 2143 patients with ruptured intracranial aneurysms: a randomised trial. Lancet. 2002 0ct;360(9342):1267-74.

8 Beck J, Rohde S, Berkefeld J, Seifert V, Raabe A. Size and location of ruptured and unruptured intracranial aneurysms measured by 3-dimensional rotational angiography. Surg Neurol. 2006 Jan;65(1):18-25.

9 Wang K, Sun Y, Li AM. Peri-procedural morbidity and mortality associated with stent-assisted coiling for intracranial aneurysms. Interv Neuroradiol. 2013 Mar;19(1):43-8.

10 Gao X, Liang G, Li Z, Wei X, Hong Q. Complications and adverse events associated with Neuroform stentassisted coiling of wide-neck intracranial aneurysms. Neurol Res. 2011 Oct;33(8):841-52. 


\section{Case Reports in Neurology}

\begin{tabular}{l|l} 
Case Rep Neurol 2020;12:161-168 \\
\hline DOI: 10.1159/000503094 & $\begin{array}{l}\text { @ } 2020 \text { The Author(s). Published by S. Karger AG, Basel } \\
\text { www.karger.com/crn }\end{array}$ \\
\hline
\end{tabular}

Daga et al.: Small Intracranial Aneurysms and Subarachnoid Hemorrhage: Is the Size Criterion for Risk of Rupture Relevant?

11 Jeong YG, Jung YT, Kim MS, Eun CK, Jang SH. Size and location of ruptured intracranial aneurysms. J Korean Neurosurg Soc. 2009 Jan;45(1):11-5.

12 Korja M, Kivisaari R, Rezai Jahromi B, Lehto H. Size and location of ruptured intracranial aneurysms: consecutive series of 1993 hospital-admitted patients. J Neurosurg. 2017 Oct;127(4):748-53.

13 Liang G, Gao X, Li Z, Wei X, Xue H. Neuroform stent-assisted coiling of intracranial aneurysms: a 5 year single-center experience and follow-up. Neurol Res. 2010 Sep;32(7):721-7.

14 Skodvin TØ, Johnsen LH, Gjertsen Ø, Isaksen JG, Sorteberg A. Cerebral Aneurysm Morphology before and after Rupture: Nationwide Case Series of 29 Aneurysms. Stroke. 2017 Apr;48(4):880-886.

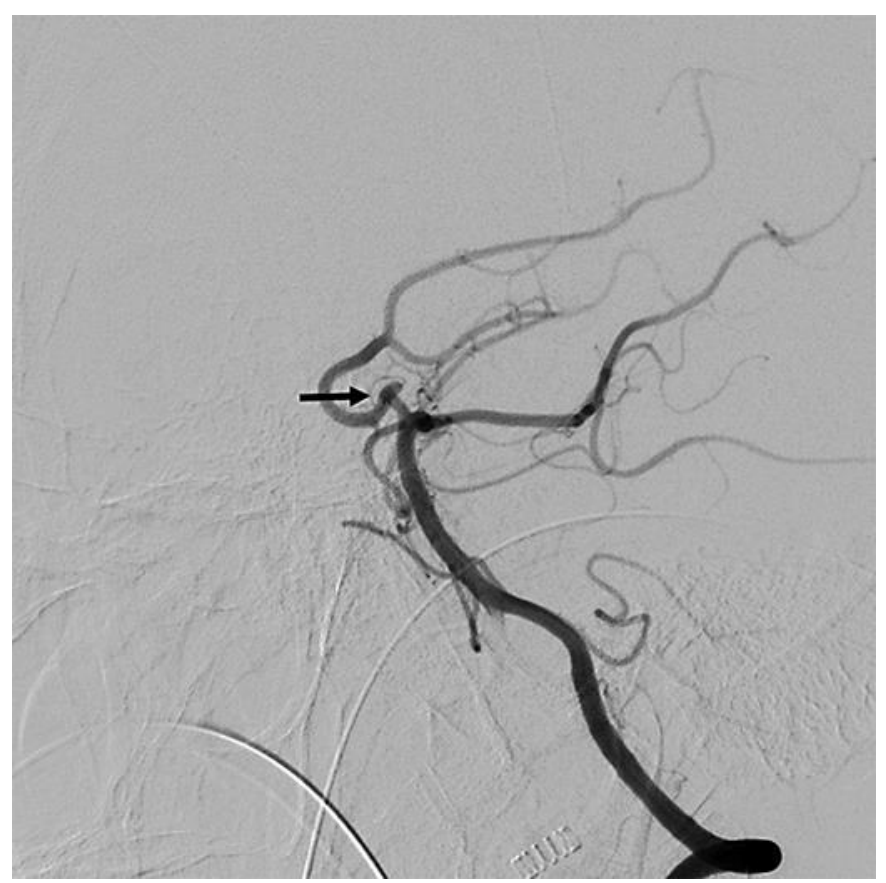

Fig. 1. Angiogram showing a 2-mm aneurysm at the right proximal PCA pointing posterolaterally. 


\section{Case Reports in Neurology}

Case Rep Neurol 2020;12:161-168

DOI: $10.1159 / 00050309$

www.karger.com/crn

Daga et al.: Small Intracranial Aneurysms and Subarachnoid Hemorrhage: Is the Size Criterion for Risk of Rupture Relevant?

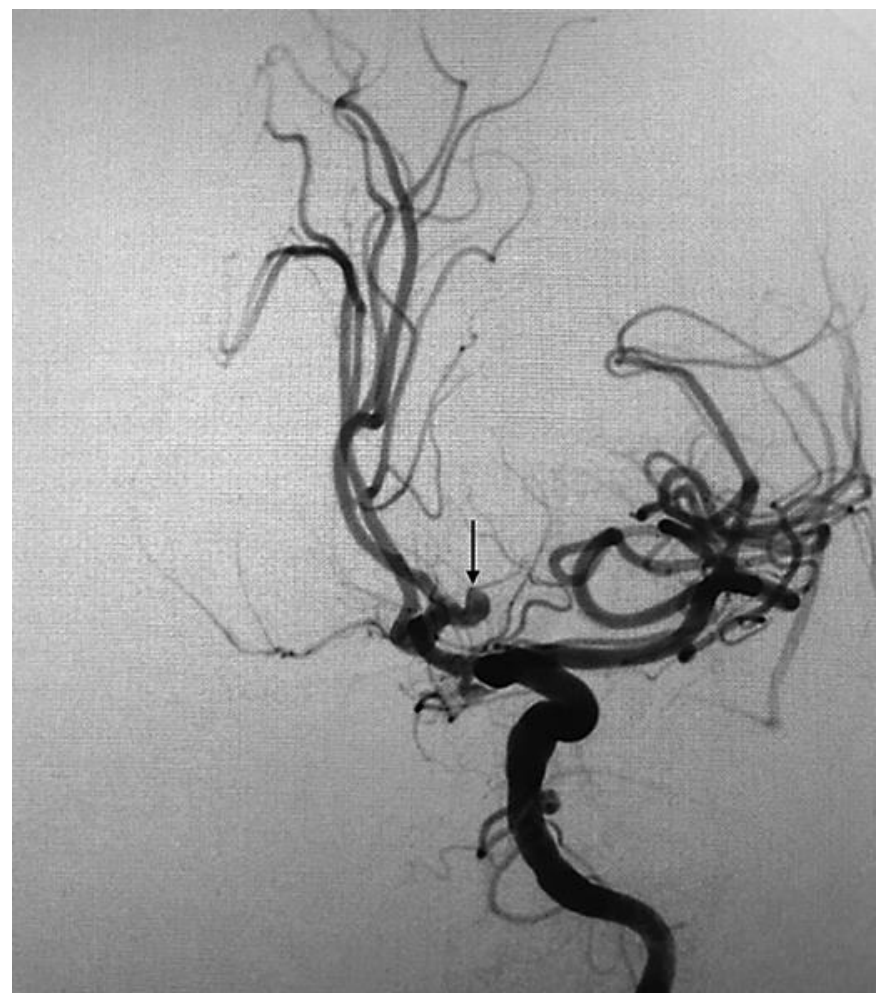

Fig. 2. Catheter angiogram showing a 3-mm AComA aneurysm. 
Case Reports in

Neurology

\begin{tabular}{l|l}
\hline Case Rep Neurol 2020;12:161-168 \\
\hline DOI: 10.1159/000503094 & $\begin{array}{l}\text { (C) 2020 The Author(s). Published by S. Karger AG, Basel } \\
\text { www.karger.com/crn }\end{array}$ \\
\hline
\end{tabular}

Daga et al.: Small Intracranial Aneurysms and Subarachnoid Hemorrhage: Is the Size Criterion for Risk of Rupture Relevant?

Table 1. The locations of intracranial aneurysms reported in other studies [9-12]

\begin{tabular}{|c|c|c|c|c|}
\hline & \multicolumn{4}{|l|}{ Study } \\
\hline & Wang et al. [9] & Gao et al. [10] & Jeong et al. [11] & Korja et al. [12] \\
\hline Cohort size, $n$ & 86 & 239 & 239 & 1,944 \\
\hline Ruptured aneurysms (\%) & $13(15.12)$ & 129 (53.97) & $239(100.00)$ & $1,944(100.00)$ \\
\hline Unruptured aneurysms (\%) & $73(84.88)$ & $110(46.03)$ & $0(0.00)$ & $0(0.00)$ \\
\hline \multicolumn{5}{|l|}{ Prevalence, \% } \\
\hline \multicolumn{5}{|l|}{ Location of aneurysm } \\
\hline ACA & 1.16 & 2.09 & 5.86 & - \\
\hline AComA & 2.33 & 5.02 & 27.62 & 32.83 \\
\hline Paraclinoid/supraclinoid segment ICA & 4.65 & 17.15 & - & - \\
\hline Cavernous segment ICA & 19.77 & 8.37 & 0.42 & - \\
\hline Ophthalmic segment ICA & 39.53 & 15.48 & 5.02 & 1.70 \\
\hline ICA bifurcation & - & 5.86 & - & 2.67 \\
\hline ICA-AChoA & - & 7.11 & 2.93 & 1.29 \\
\hline MCA & 3.49 & - & 25.52 & 33.13 \\
\hline PComA & 20.93 & 20.50 & 21.76 & 14.35 \\
\hline PCA & 1.16 & - & 0.42 & - \\
\hline BA (including at apex) & 3.49 & 7.53 & 5.44 & 4.42 \\
\hline PICA & - & 2.09 & 3.35 & 3.24 \\
\hline SCA (including BA-SCA) & 1.16 & - & 0.84 & 1.13 \\
\hline Others & 2.33 & 8.79 & 0.84 & 5.25 \\
\hline
\end{tabular}

ACA, anterior cerebral artery; AcomA, anterior communicating artery; ICA, internal carotid artery; AChoA, anterior choroidal artery; MCA, middle carotid artery; PComA, posterior communicating artery; PCA, posterior cerebral artery; PICA, posterior inferior cerebellar artery; SCA, superior cerebellar artery; BA, basilar artery. 